\title{
Interactive comment on "Uncertainty analysis of floodplain friction in hydrodynamic models" by Guilherme Dalledonne et al.
}

\section{Guilherme Dalledonne et al.}

guilherme.dalledonne@baw.de

Received and published: 5 June 2019

Dear Referee \#2,

thank you very much for your comments.

One limit concerns the confusion on the used symbols: some of them are not clearly defined, both in the text and in the tables captions (e.g. $H, D, t, x, y, \ldots)$, and some other are used to indicate more than one quantity (e.g., d). Moreover, the authors use acronyms before they are defined.

Thank you for pointing that out. We modified the manuscript accordingly. 
I was wondering about the meaning of the term "prediction interval" and if it is HESSD considered as an "uncertainty band". The comment of the previous reviewer and the reply of the authors shed light on this issue.

It seems to me that the term "uncertainty band" refers to the same quantity as "prediction band" or "prediction interval". I would still stick to the latter to avoid further misunderstanding regarding the term "uncertainty", and as "prediction interval" seems to be more widely used according to Google. Nevertheless the definition given in Section 3 was improved.

Minor comments: - explain what "with a probability of occurrence larger than HQ5" means. - use always the past tense or the present tense throughout the manuscript.

We modified the manuscript accordingly.

\section{Reference}

Lawless, J. and Fredette, M. (2005). Frequentist Prediction Intervals and Predictive Distributions. Biometrika, 92(3), 529-542.

Please also note the supplement to this comment: https://www.hydrol-earth-syst-sci-discuss.net/hess-2019-159/hess-2019-159-AC4supplement.pdf

Interactive comment on Hydrol. Earth Syst. Sci. Discuss., https://doi.org/10.5194/hess-2019159, 2019. 